\title{
Intra-arterial gas, a clue for diagnosis of infective aortic aneurysm
}

\author{
Daisuke Omura ${ }^{1}$, Hideharu Hagiya ${ }^{1}$, Masatoshi Ogata ${ }^{2}$, Yoshio Sakane ${ }^{2}$, Ryuichi Matsuo ${ }^{2}$, \\ Harushige Nakatsukasa ${ }^{2}$, and Fumio Otsuka ${ }^{3}$ \\ ${ }^{1}$ Okayama University Hospital \\ ${ }^{2}$ Affiliation not available \\ ${ }^{3}$ Okayama Daigaku - Shikata Campus
}

July 1, 2020

A 70-year-old diabetic woman was admitted to our hospital with a complaint of high fever accompanying shaking chills for three days. The patient had no abdominal symptoms and no history of eating raw food. The patient's body temperature was increased to $39^{\circ} \mathrm{C}$, and blood analysis showed elevations of leukocytes $(17,400 / \mu \mathrm{L})$ and C-reactive protein $(16.5 \mathrm{mg} / \mathrm{dL})$. Computed tomography revealed air density spots in the aortic wall (Fig A ), and Salmonella enteritidis serotype O9 was detected by blood culture. Under a tentative diagnosis of Salmonella-induced infective aortic aneurysm, the patient underwent antibiotic treatment with ampicillin/sulbactam. On day 11, the air had disappeared and the aortic wall showed a varicose deformity, leading to a differential diagnosis of infective aortic aneurysm (Fig B ). The patient recovered completely with 8-week antibiotic therapy without any operation.

Cases of infective aortic aneurysms account for only about $1 \%$ to $3 \%$ of total cases of aortic aneurysm. However, the case fatality has been reported to be as high as 18 percent in two years ${ }^{1}$, and an early diagnosis is essential. Salmonella species are known as a common pathogen of the crucial infection ${ }^{2}$, and so clinicians should pay attention to the development of the disease.

\section{References}

1. Kan CD, Lee HL, Yang YJ. Outcome after endovascular stent graft treatment for mycotic aortic aneurysm: a systematic review. J Vasc Surg. 2007;46(5):906.

2. Hsu RB, Chen RJ, Wang SS, Chu SH. Infected aortic aneurysms: Clinical outcome and risk factor analysis. J. Vasc. Surg. 2004; 40: 30-35.

Figure Legend

The abdominal computed tomography on admission (A) and on day 11 (B).

Air-density spots were found in the aortic wall (A, arrowheads), which later disappeared and outpouching of the arterial wall emerged at the corresponding site (B).

\section{Hosted file}

Omura_salmonella_endocarditis (1).pptx available at https://authorea.com/users/332755/ articles/465239-intra-arterial-gas-a-clue-for-diagnosis-of-infective-aortic-aneurysm 